\title{
The influence of bypass temperature on the systemic inflammatory response and organ injury after pediatric open surgery: A randomized trial
}

\author{
Christian F. Stocker, MD, ${ }^{\text {a,b }}$ Lara S. Shekerdemian, MD, ${ }^{\text {b,c,f }}$ Stephen B. Horton, PhD, ${ }^{\text {d,f }}$ \\ Katherine J. Lee, PhD, ${ }^{\mathrm{g}}$ Rob Eyres, MD, ${ }^{\mathrm{e}}$ Yves D’Udekem, MD, PhD, ${ }^{\mathrm{d}, \mathrm{f}}$ and Christian P. Brizard, MD ${ }^{\mathrm{b}, \mathrm{d}, \mathrm{f}}$
}

\begin{abstract}
Objective: Systemic cooling for cardiopulmonary bypass is widely used to attenuate the systemic inflammatory response syndrome and organ injury in children after open surgery. We compared the effects of moderate $\left(24^{\circ} \mathrm{C}\right)$ and mild $\left(34^{\circ} \mathrm{C}\right)$ hypothermia during bypass on markers of the systemic inflammatory response syndrome and organ injury, and on clinical outcome after corrective surgery for congenital heart disease.
\end{abstract}

\begin{abstract}
Methods: Sixty-six children (mean age, $6.8 \pm 5.7$ months; mean weight, $6.2 \pm 2.3 \mathrm{~kg}$ ) were randomized to $24^{\circ} \mathrm{C}$ or $34^{\circ} \mathrm{C}$ bypass temperature during cardiac surgery. Perfusion strategies were otherwise strictly identical. Clinical data and blood samples were collected before bypass, 5 minutes after aortic crossclamp release, and 4, 24, and 48 hours after bypass. Patients were followed up until discharge from the hospital.

Results: In the 54 children with outcome data, bypass temperature did not influence the duration of mechanical ventilation between the $24^{\circ} \mathrm{C}$ group and the $34^{\circ} \mathrm{C}$ group (median [interquartile range] 22 [13-40] hours vs 14 [8-40] hours, $P=.14$ ), intensive care unit stay (43 [24-49] hours vs 29 [23-47] hours, $P=.79$ ), blood loss (29 [20-38] $\mathrm{mL} / \mathrm{kg}$ vs 23 [13-38] $\mathrm{mL} / \mathrm{kg}, P=.36$ ), or incidence of postoperative infection $(9 \% \mathrm{vs} 11 \%$, $P=1.0$ ). There was no evidence of an influence of bypass temperature on the markers of acute inflammation, innate immune response, organ injury, coagulation, or hemodynamics.
\end{abstract}

Conclusions: There is no evidence that the systemic inflammatory response syndrome and organ injury after pediatric open surgery are influenced by bypass temperature. The routine use of hypothermic bypass may not be warranted in the pediatric population. (J Thorac Cardiovasc Surg 2011;142:174-80)

Cardiopulmonary bypass (CPB) used for adult cardiac surgery is now uniformly carried out under normothermic conditions. The temperatures applied in pediatric CPB vary significantly, ranging from deep hypothermia to normothermia. The lack of a consistent approach to CPB temperature in pediatric practice is related to a lack of supportive evidence from well-designed randomized trials. ${ }^{1,2}$ This prospective, randomized, blinded study compared the effects of mild $\left(34^{\circ} \mathrm{C}\right)$ and moderate hypothermia $\left(24^{\circ} \mathrm{C}\right)$ during $\mathrm{CPB}$ on the clinical outcome, markers of systemic inflammatory

From the Pediatric Intensive Care Unit, ${ }^{a}$ Mater Children's Hospital, Brisbane, Australia; The Australia New Zealand Children's Heart Research Center, ${ }^{\mathrm{b}}$ Melbourne, Australia; Departments of Pediatric Intensive Care, ${ }^{\mathrm{c}}$ Cardiac Surgery, ${ }^{\mathrm{d}}$ and Anaesthesiology, ${ }^{\mathrm{e}}$ The Royal Children's Hospital, Melbourne, Australia; University of Melbourne, ${ }^{\mathrm{f}}$ Melbourne, Australia; and Clinical Epidemiology and Biostatistics Unit, ${ }^{\mathrm{g}}$ Murdoch Children's Research Institute, Melbourne, Australia.

This project has been financed by the Australia New Zealand Children's Heart Research Center. Dr Stocker received financial support for a research fellowship from the Mach Gaensslen Foundation Switzerland and from Novartis Pharma Switzerland.

Disclosures: Authors have nothing to disclose with regard to commercial support. Received for publication Aug 6, 2009; revisions received Oct 22, 2010; accepted for publication Jan 24, 2011; available ahead of print March 21, 2011.

Address for reprints: Christian P. Brizard, MD, Director Cardiac Surgery Department, The Royal Children's Hospital, Flemington Road, Parkville VIC 3052, Australia (E-mail: Christian.Brizard@ rch.org.au).

$0022-5223 / \$ 36.00$

Copyright (c) 2011 by The American Association for Thoracic Surgery doi:10.1016/j.jtcvs.2011.01.059 response syndrome (SIRS), and the development of postoperative organ injury in a group of infants and children undergoing open surgery.

\section{MATERIAL AND METHODS}

\section{Enrollment of Patients}

This trial was approved by the Human Research Ethics Committee of The Royal Children's Hospital ( $\mathrm{RCH})$, Melbourne. Written informed consent was obtained from the parents before the surgery. Term neonates, infants, and children with body weight up to $12 \mathrm{~kg}$ undergoing elective corrective surgery for congenital heart disease on CPB were considered for inclusion. Excluded were patients with suspected or proven infection, the likely need for intraoperative deep hypothermia, requirement of mechanical ventilation (MV) within 48 hours before surgery, and CPB surgery within the preceding 6 months.

\section{Study Design}

This randomized study was performed in the operating theaters and pediatric intensive care unit at the $\mathrm{RCH}$. Participants were randomized to a body temperature of either $24^{\circ} \mathrm{C}$ or $34^{\circ} \mathrm{C}$ during CPB. With the exception of the perfusionist undertaking the case, none of the other treating clinicians or investigators were made aware as to the group allocation before data analysis. However, because the surgeon had direct contact with the patient during $\mathrm{CPB}$, it was likely that he would have deduced the group allocation from the temperature of the tissues and blood during surgery. The study commenced with baseline measurements and blood sampling after induction of anesthesia before the onset of CPB. Further measurements were obtained 5 minutes after release of the aortic crossclamp and 4, 24, and 48 hours after separation from CPB. 


$$
\begin{aligned}
& \text { Abbreviations and Acronyms } \\
& \text { CPB }=\text { cardiopulmonary bypass } \\
& \text { IL }=\text { interleukin } \\
& \text { mHLA }=\text { monocyte human leucocyte antigen } \\
& \text { MV }=\text { mechanical ventilation } \\
& \text { RCH }=\text { Royal Children's Hospital } \\
& \text { SIRS }=\text { systemic inflammatory response } \\
& \text { syndrome } \\
& \text { TLR }=\text { toll-like receptor } \\
& \text { TNF }=\text { tumor necrosis factor }
\end{aligned}
$$

\section{Operative and Weaning Protocol}

All participants received intravenous methylprednisolone $(25 \mathrm{mg} / \mathrm{kg})$ at induction. A single oxygenator (RX05, Terumo Corp, Tokyo, Japan) was used for all participants, as well as our standard CPB circuit and priming protocol. Blood was added to the prime to achieve a hematocrit of $30 \%$. Heparin therapy was adjusted to maintain an activated clotting time greater than 400 seconds. Aprotinin was given in a standard dose regimen, and an $\alpha$-stat blood gas management was applied. Myocardial protection was achieved with intermittent blood cardioplegia at $25^{\circ} \mathrm{C}$. Nasopharyngeal and esophageal temperatures were measured continuously and kept within $1{ }^{\circ} \mathrm{C}$ of target $\mathrm{CPB}$ temperature. Weaning from $\mathrm{CPB}$ was commenced at a nasopharyngeal temperature of $36^{\circ} \mathrm{C}$. All patients were treated with modified ultrafiltration to a total volume of $100 \mathrm{~mL} / \mathrm{kg}^{3 .-5}$ Weaning from MV was managed by experienced medical staff 24 hours per day according to predefined clinical parameters including clinical condition, blood gases, acid-base balance, hemodynamic stability, and wakefulness.

\section{Study Outcomes}

Primary and secondary outcomes. The primary outcome of the study was the duration of postoperative MV calculated from the time of admission to the pediatric intensive care unit after surgery. Secondary end points included clinical outcomes, organ injury, hemodynamics, inotropic score, ${ }^{6}$ coagulation profile, and markers of inflammation. Markers of organ injury included serum lactate, oxygenation index, creatinine, microalbuminuria, and plasma S-100B. Inflammatory markers included tumor necrosis factor (TNF)- $\alpha$, interleukin (IL)-6 and 10, monocyte human leucocyte antigen (mHLA)-DR, toll-like receptor (TLR)-2 and TLR-4, C-reactive protein, total white cell count, and immature-to-total neutrophil ratio.

\section{Statistical Analysis}

The sample size calculation was based on the primary outcome of duration of MV. Historic data on 24 neonates undergoing the arterial switch procedure at The $\mathrm{RCH}$ who were given prophylactic methylprednisolone showed a geometric mean duration of MV of 40 hours with a standard deviation of 0.5 on the $\log$-scale. The trial was powered to find a reduction of 12 hours in the moderate group compared with the mild group, thought to be clinically important according to a round-table discussion of experts in the field. A reduction from 40 to 28 hours (3.69 to 3.33 on the log-scale) corresponds to a sample size of 33 per group (assuming a standard deviation of 0.5 on the log-scale, $80 \%$ power, and $5 \%$ significance). The final sample size of 27 per group provides $73 \%$ power to detect a difference of 12 hours in the primary outcome and $80 \%$ power to find a difference of 20 hours. Outcomes were compared using $t$ tests and Wilcoxon ranksum tests for continuous data, and chi-square tests for categoric data using a per protocol analysis (excluding major protocol violations) where outcome data were available. Serial measurement outcomes were compared using repeated-measures analysis of variance, including group-by-time in-
TABLE 1. Patient characteristics

\begin{tabular}{lcc}
\hline & $\mathbf{2 4}^{\circ} \mathbf{C}(\mathbf{n}=\mathbf{2 7})$ & $\mathbf{3 4}^{\circ} \mathbf{C}(\mathbf{n}=\mathbf{2 7})$ \\
\hline Age (d), mean (SD) & $185.2 \pm 165.4$ & $223.6 \pm 175.7$ \\
Male gender, n (\%) & $16(59 \%)$ & $16(59 \%)$ \\
Weight (kg), mean (SD) & $6.15 \pm 2.48$ & $6.37 \pm 2.37$ \\
Diagnosis, n & & \\
$\quad$ AVSD & 11 & 12 \\
Tetralogy of Fallot & 6 & 8 \\
Pulmonary atresia & 1 & 1 \\
$\quad$ VSD & 2 & 0 \\
$\quad$ IVS & & \\
D-TGA & 4 & 1 \\
$\quad$ VSD & 3 & 3 \\
$\quad$ IVS & 0 & 1 \\
TAPVD & 0 & \\
Truncus arteriosus & & \\
\hline
\end{tabular}

$S D$, Standard deviation; $A V S D$, atrioventricular septal defect; $I V S$, intact ventricular septum; D-TGA, D-transposition of the great arteries; TAPVR, total anomalous pulmonary venous return.

teraction to identify differences at specific time points where outcome data was available. All descriptive and inferential statistics were performed using commercial software (SAS v9.1, SAS Institute Inc, Cary, NC).

\section{RESULTS}

Between March 2003 and July 2005, 66 patients were recruited for the study. One patient was excluded after

TABLE 2. Baseline measurements (pre-cardiopulmonary bypass)

\begin{tabular}{lcc}
\hline & $\begin{array}{c}\mathbf{2 4}^{\circ} \mathbf{C} \\
(\mathbf{n}=\mathbf{2 7})\end{array}$ & $\begin{array}{c}\mathbf{3 4}^{\circ} \mathbf{C} \\
(\mathbf{n}=\mathbf{2 7})\end{array}$ \\
\hline Hemodynamic indices & & \\
Heart rate (beats/min) & $128 \pm 24$ & $124 \pm 27$ \\
Systolic arterial blood pressure $(\mathrm{mm} \mathrm{Hg})$ & $84 \pm 18$ & $76 \pm 10$ \\
Mean arterial blood pressure $(\mathrm{mm} \mathrm{Hg})$ & $59 \pm 12$ & $54 \pm 11$ \\
Diastolic arterial blood pressure $(\mathrm{mm} \mathrm{Hg})$ & $43 \pm 9$ & $41 \pm 8$ \\
Inotropic score $(\mu \mathrm{g} / \mathrm{kg} / \mathrm{min})$ & $0 \pm 0$ & $0 \pm 0$ \\
Lactate $(\mathrm{mmol} / \mathrm{L})$ & $1.6 \pm 0.6$ & $1.7 \pm 1.1$ \\
Acute inflammation & & \\
Total white blood cell count $\left(\times 10^{9} / \mathrm{L}\right)$ & $8.5 \pm 3.2$ & $8.3 \pm 3.8$ \\
Immature-to-mature neutrophil ratio & $0.05 \pm 0.03$ & $0.07 \pm 0.07$ \\
C-reactive protein $(\mathrm{mg} / \mathrm{L})$ & $8.6 \pm 2.6$ & $8.7 \pm 2.7$ \\
TNF- $\alpha(\eta \mathrm{g} / \mathrm{L})$ & $3.7 \pm 2.9$ & $3.9 \pm 2.2$ \\
IL-6 $(\eta \mathrm{g} / \mathrm{L})$ & $6.9 \pm 5.7$ & $10.4 \pm 13.7$ \\
IL-10 $(\eta \mathrm{g} / \mathrm{L})$ & $7.3 \pm 5.1$ & $6.9 \pm 3.2$ \\
Organ injury & & \\
Oxygenation index & $4.7 \pm 3.5$ & $3.9 \pm 3.5$ \\
Creatinine $(\mu \mathrm{mol} / \mathrm{L})$ & $35 \pm 21$ & $34 \pm 8$ \\
Microalbuminuria $(\mathrm{mg} / \mathrm{mmol})$ & $24 \pm 43$ & $6.4 \pm 9.4$ \\
S100B $(\mu \mathrm{g} / \mathrm{L})$ & $0.46 \pm 0.37$ & $0.45 \pm 0.44$ \\
Coagulation profile & & \\
Prothrombin time $(\mathrm{s})$ & $12.2 \pm 6.2$ & $11.8 \pm 6.5$ \\
Activated partial & $47 \pm 9$ & $48 \pm 12$ \\
$\quad$ thromboplastin time $(\mathrm{s})$ & $2.3 \pm 0.6$ & $2.4 \pm 0.8$ \\
Fibrinogen $(\mathrm{g} / \mathrm{L})$ & $343 \pm 113$ & $392 \pm 119$ \\
Platelet count $\left(\times 10^{9} / \mathrm{L}\right)$ & & \\
\hline
\end{tabular}

$T N F$, Tumor necrosis factor; $I L$, interleukin. Data expressed as mean \pm standard deviation. 
TABLE 3. Intraoperative characteristics

\begin{tabular}{|c|c|c|c|c|}
\hline & $24^{\circ} \mathrm{C}(\mathbf{n}=\mathbf{2 7})$ & $34^{\circ} \mathrm{C}(\mathrm{n}=27)$ & $\begin{array}{c}\text { Difference in } \\
\text { means/medians }\left(95 \% \mathrm{CI}^{*}\right)\end{array}$ & $P$ value \\
\hline CPB time $(\min )-$ median $(\mathrm{IQR}) \S$ & $141(96-171)$ & $106(86-163)$ & -35 & $.16 \dagger$ \\
\hline Aortic crossclamp time $(\min )-$ mean $\pm \operatorname{SD} \S$ & $83 \pm 31$ & $75 \pm 31$ & $-8(-25$ to 10$)$ & $.38 \ddagger$ \\
\hline Blood prime volume $(\mathrm{mL} / \mathrm{kg})-$ mean $\pm \mathrm{SD} \S$ & $76 \pm 38$ & $75 \pm 35$ & $-2(-22$ to 19$)$ & $.87 \ddagger$ \\
\hline Time to normothermia (min) - median (IQR) & $30(21-43)$ & $14(10-15)$ & -16 & $<.001 \dagger$ \\
\hline Ultrafiltration volume $(\mathrm{mL} / \mathrm{kg})$ - median $(\mathrm{IQR}) \S$ & $182(54-364)$ & $147(85-318)$ & -35 & $.94+$ \\
\hline
\end{tabular}

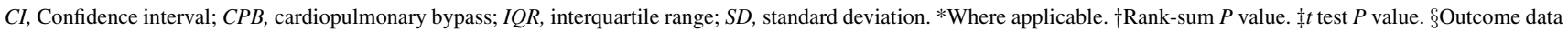
available for 26 patients in the $24^{\circ} \mathrm{C}$ arm and 25 patients in the $24^{\circ} \mathrm{C}$ arm.

randomization because of cardiac arrest at induction of anesthesia. Six participants in the moderate hypothermia $\left(24^{\circ} \mathrm{C}\right)$ and 5 patients in the mild hypothermia $\left(34^{\circ} \mathrm{C}\right)$ group were excluded from subsequent analysis because of protocol violations. This included 2 patients who returned from the operating room on extracorporeal life support, 2 patients who required more than $1 \mathrm{CPB}$ course in the same operating session, and 7 patients in whom the surgeon chose to alter the temperature because of change in perfusion requirements (low-flow CPB or circulatory arrest, 3 patients in the moderate group and 4 patients in the mild hypothermia group). Thus, 27 patients in each group are included in the analysis.

\section{Baseline and Intraoperative Characteristics}

Patient demographics, baseline measurements, and intraoperative characteristics were similar in both groups. As would be expected, mean CPB time was longer in the moderate hypothermia group because of the longer period required for rewarming from target $\mathrm{CPB}$ temperature to normothermia (Tables 1-3).

\section{Clinical Outcomes}

The results show a tendency toward a reduction in the median duration of MV of 8 hours in the mild hypothermia group compared with the moderate hypothermia group (median [interquartile range] 22 [13-40] hours at $24^{\circ} \mathrm{C}$ vs 14 hours [8-40] at $34^{\circ} \mathrm{C}, P=.14$ ), but little evidence of a difference in any of the other clinical outcomes (Table 4).

\section{Markers of Inflammation}

The total white cell count decreased in both groups from baseline until crossclamp removal, with a greater decrease in the $24^{\circ} \mathrm{C}$ group (overall $P=.04$ ) (Figure 1). The maximum postoperative temperature was similar in both groups, and although an inflammatory response was seen in both groups, there was no evidence for an influence of CPB temperature on immature-to-total neutrophil ratio, C-reactive protein, fibrinogen, TNF- $\alpha$, IL-6, or IL-10, or in expression of TLR-2, TLR-4, or mHLA-DR (all $P>.1$ ).

\section{Hemodynamics, Markers of Organ Injury, and Coagulation}

There was no evidence of a difference in changes in heart rate, mean arterial blood pressure, inotropic score, or serum lactate between the 2 groups throughout the study period. There was also no evidence of a difference in the changes in oxygenation index, serum creatinine, microalbuminuria, or S100B. Coagulation profiles and platelet count were similar in both groups (all $P>.1$ ) (Figure 2).

\section{DISCUSSION}

This study has addressed an important and previously unresolved clinical question regarding the most appropriate temperature during pediatric $\mathrm{CPB} .^{2,7-9}$ Although moderate hypothermia at $28^{\circ} \mathrm{C}$ has been shown to offer better protection from postoperative SIRS than normothermia $\left(37^{\circ} \mathrm{C}\right)$ during $\mathrm{CPB}$ in the experimental setting, this has never been shown to translate into improved outcomes in the clinical setting. ${ }^{10,11}$ Thus, following the precedent

TABLE 4. Clinical outcomes

\begin{tabular}{lccc}
\hline & $\mathbf{2 4}{ }^{\circ} \mathbf{C}$ & $\mathbf{3 4}{ }^{\circ} \mathbf{C}$ & \\
& $(\mathbf{n}=\mathbf{2 7})$ & $(\mathbf{n}=\mathbf{2 7})$ & $\boldsymbol{P}$ \\
\hline Duration of MV (h) & $22(13-40)$ & $14(8-40)$ & .14 \\
& $(\mathrm{n}=25)$ & $(\mathrm{n}=25)$ & \\
Time on supplemental & $47(33-69)$ & $47(66-96)$ & .95 \\
oxygen (h) & $(\mathrm{n}=22)$ & $(\mathrm{n}=20)$ & \\
Time to removal of last & $44(39-46)$ & $45(40-60)$ & .38 \\
wound/chest drain (h) & $(\mathrm{n}=20)$ & $(\mathrm{n}=21)$ & \\
Total postoperative blood & $29(20-38)$ & $23(13-38)$ & .36 \\
loss (mL/kg) & $(\mathrm{n}=24)$ & $(\mathrm{n}=25)$ & \\
Total postoperative & $20(6-26)$ & $17(2-27)$ & .52 \\
transfusion (mL/kg) & $(\mathrm{n}=24)$ & $(\mathrm{n}=26)$ & \\
Delayed chest closure or & 0 & 0 & \\
reopening (no. of patients) & $(\mathrm{n}=27)$ & $(\mathrm{n}=27)$ & \\
Postoperative infection & $2(9 \%)$ & $3(11 \%)$ & .10 \\
(no. of patients, \%) & $(\mathrm{n}=27)$ & $(\mathrm{n}=27)$ & \\
Stay in PICU (h) & $(24-49)$ & $29(23-47)$ & .79 \\
& $(\mathrm{n}=24)$ & $(\mathrm{n}=23)$ & \\
Stay in hospital (h) & $145(112-193)$ & $12(97-169)$ & .18 \\
& $(\mathrm{n}=24)$ & $(\mathrm{n}=23)$ & \\
\hline
\end{tabular}

$M V$, Mechanical ventilation; $P I C U$, pediatric intensive care unit. Values expressed as median (interquartile range) unless otherwise specified. 

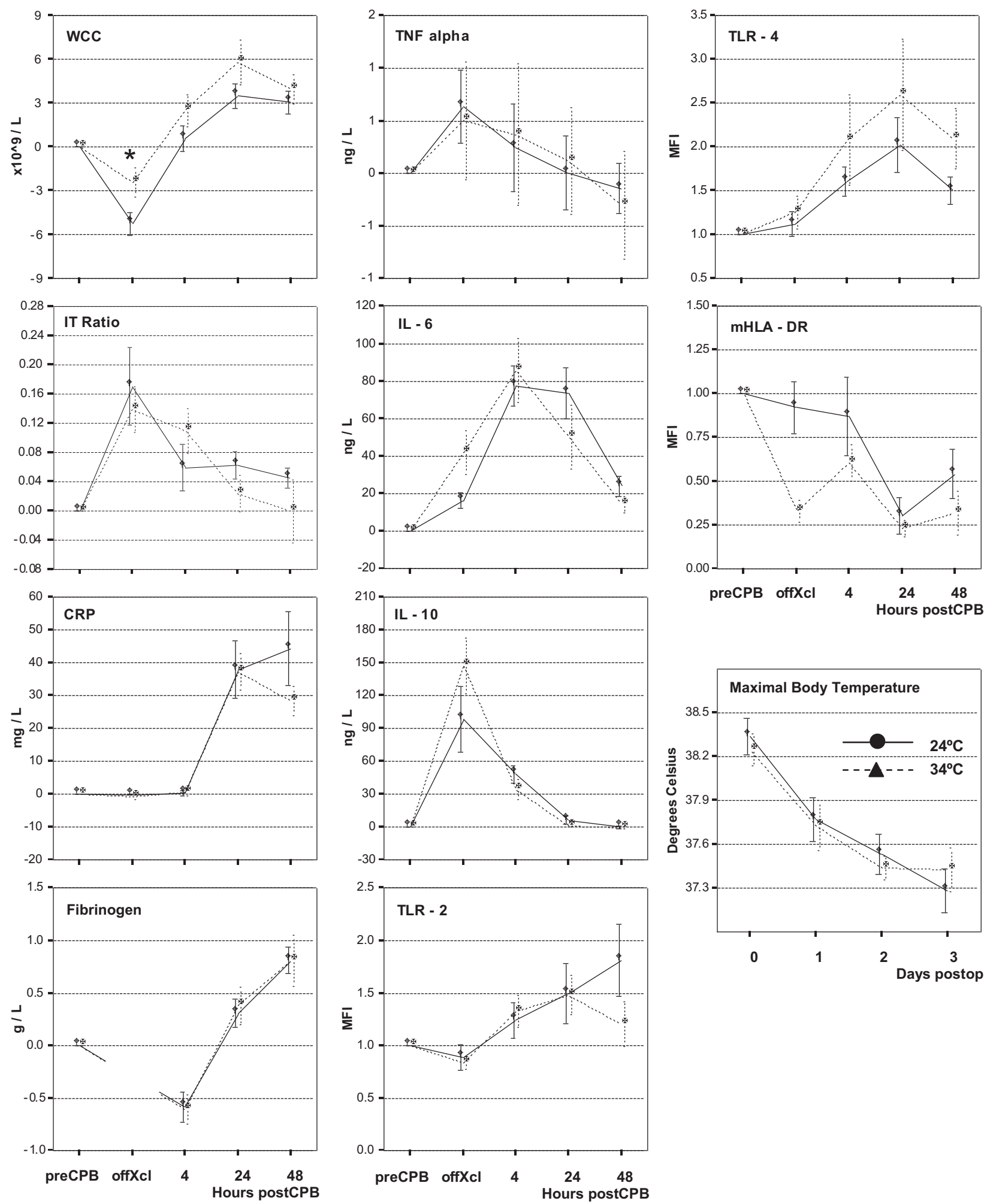

FIGURE 1. Markers of acute inflammation. Absolute changes in markers for acute inflammation, acute phase reaction, and innate immunity from baseline measurements; data are expressed as mean \pm standard error. $* P<.05$ for differences between treatment groups. TLR-2, TLR-4, and mHLA-DR data were only available for 8 patients in each group at each time point. The analysis used all available data. $S E$, Standard error; $C P B$, cardiopulmonary bypass; off $x c l$, crossclamp off; $A P$, arterial pressure; $T N F-\alpha$, tumor necrosis factor- $\alpha ; I L$, interleukin; $m H L A-D R$, monocyte human leucocyte antigen-DR; TLR-2/-4, toll-like receptor 2/4; CRP, C-reactive protein; WCC, total white cell count; ITR, immature-to-total neutrophil ratio. 

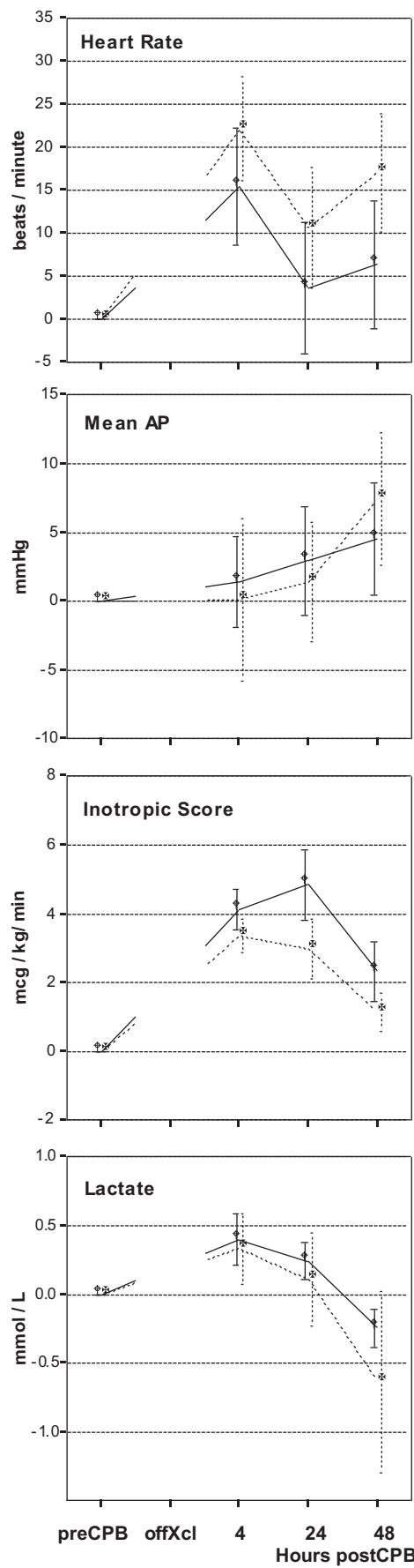
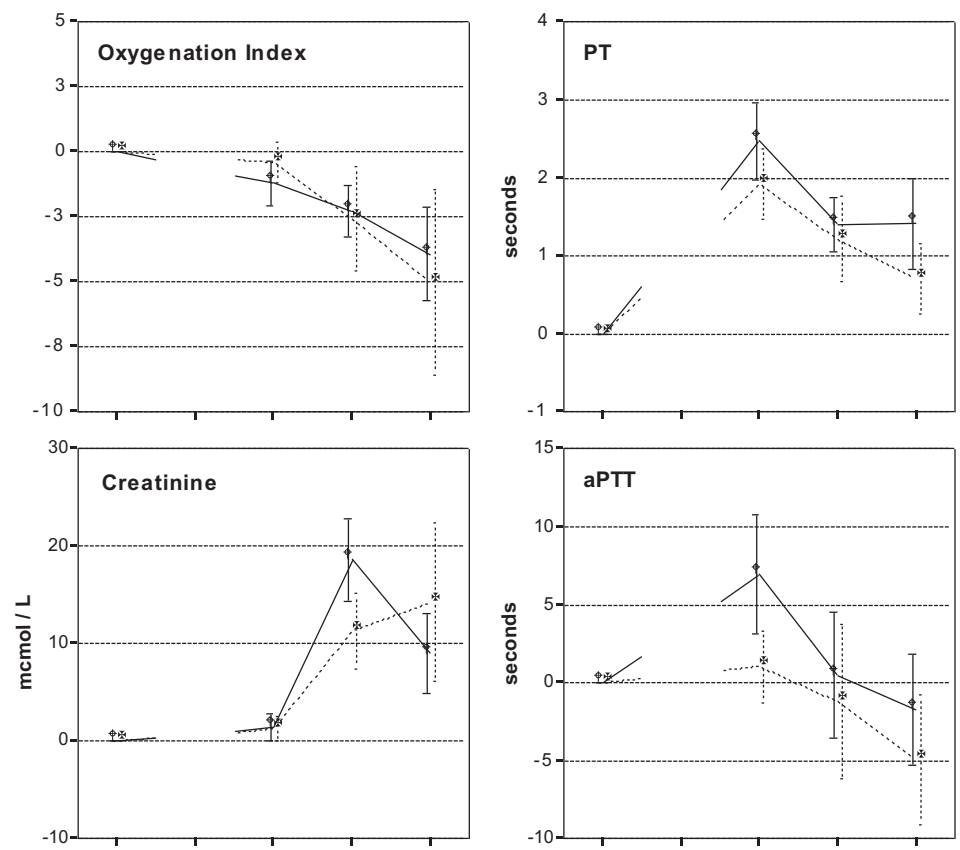
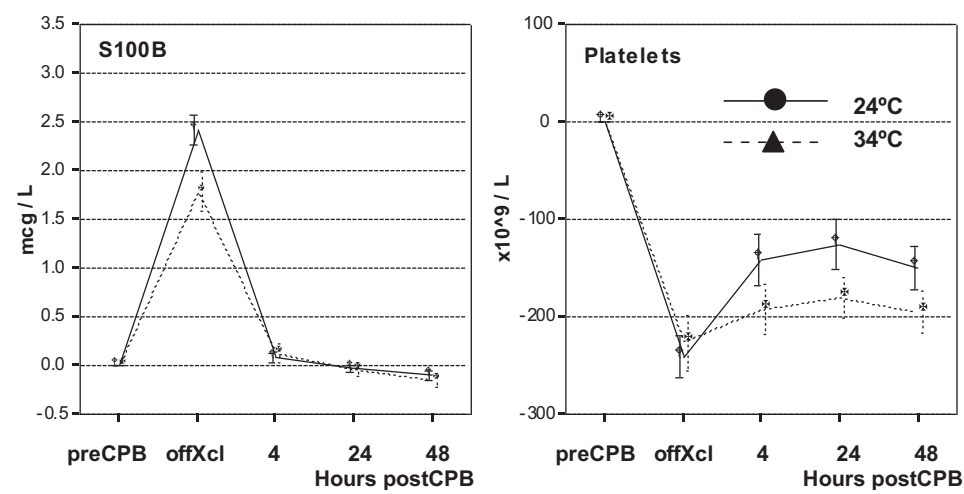

FIGURE 2. Hemodynamics, markers of organ injury, and coagulation profile. Absolute changes in hemodynamic indices, markers for organ injury, and coagulation from baseline measurements; data are expressed as mean \pm standard error. In the $24^{\circ} \mathrm{C}$ and $34^{\circ} \mathrm{C}$ arms, heart rate data were missing for 15 time points in 7 patients and for 12 time points in 7 patients, respectively; mean arterial pressure data were missing for 18 time points in 9 patients and 22 time points in 16 patients, respectively; oxygenation index data were missing for 47 time points in 23 patients and 45 time points in 22 patients, respectively; lactate data were missing for 30 time points in 18 patients and 34 time points in 20 patients, respectively; inotropic score data were missing for 9 time points in 5 patients and 4 time points in 3 patients, respectively; creatinine data were missing for 52 time points in 16 patients and 42 time points in 15 patients, respectively; microalbuminuria data were missing for 28 time points in 12 patients and 24 time points in 8 patients, respectively; S100B data were missing for 6 time points in 2 patients and 5 time points in 3 patients, respectively; prothrombin time data were missing for 21 time points in 11 patients and 19 time points in 8 patients, respectively; activated partial thromboplastin time data were missing for 21 time points in 12 patients and 22 time points in 9 patients, respectively; and platelet count data were missing for 23 time points in 11 patients and 21 time points in 7 patients, respectively. $S E$, Standard error; $C P B$, cardiopulmonary bypass; off $x c l$, crossclamp off; AP, arterial pressure; $P T$, prothrombin time; $a P T T$, activated partial thromboplastin time. 
from adult cardiac surgery, there has been a long-standing need to reassess the role of hypothermic CPB during pediatric open surgery. ${ }^{1,2,7,9}$

This study has shown that moderate hypothermia at $24^{\circ} \mathrm{C}$ does not offer any advantages over mild hypothermia at $34^{\circ} \mathrm{C}$ during pediatric $\mathrm{CPB}$ for repair of congenital heart disease, in terms of the postoperative clinical course and severity of SIRS or markers of organ injury. Moreover, there was a tendency toward a shorter duration of MV with mild hypothermia. The depth of hypothermia during CPB did not influence the risk of postoperative bleeding, blood product transfusion requirements, or infection. As expected, there was a trend toward a shorter duration of CPB in the mildly hypothermic group, although this was related to the shorter duration of the rewarming period.

When considering the biochemical and cellular manifestations of inflammation, CPB resulted in a marked acute phase reaction in all children, but this was not influenced by temperature. In keeping with our previous observations and those of others, CPB also resulted in activation of the toll-like receptor pathways (TLR-2, TLR-4) and in deactivation of circulating monocytes (mHLA-DR). ${ }^{12,13}$ However, these markers were not influenced by the temperature during $\mathrm{CPB}$. We were particularly interested to find that TNF- $\alpha$, a proinflammatory mediator that is widely proposed as an important factor leading to the inflammatory response to $\mathrm{CPB},{ }^{14}$ was not influenced by CPB in either group. This may in part reflect our institutional perfusion protocol that includes some antiinflammatory strategies, including steroid administration and modified ultrafiltration.

Hypothermia has been widely used in clinical practice to offer organ protection when perfusion may be jeopardized. Hypothermia has been applied during open surgery with the aim of providing organ protection for approximately 50 years. ${ }^{15}$ In our study, we did not observe any difference in any clinical or biochemical markers of endorgan injury between the 2 study groups. This observation is consistent with the findings in 2 other recent clinical trials examining the effects of bypass temperature on organ injury in pediatric open surgery. ${ }^{1,16}$ We were encouraged that we did not observe a delayed increase of S100B, a marker of neuronal injury, because this is thought to correlate with brain injury and subsequent neurologic outcome. ${ }^{17}$ As would be expected, there was postoperative deterioration in lung and renal function, but again, this was not influenced by the CPB temperature. Similarly, the transient microalbuminuria early after bypass indicates a significant capillary leak, although independent of bypass temperature.

There have been 3 other clinical investigations of the role of hypothermic CPB in pediatric open surgery that are of relevance. ${ }^{1,16,18}$ Caputo and colleagues ${ }^{1}$ used biochemical and molecular markers of outcome and concluded that there was a need for a prospective trial with clinical end points.
Rasmussen and colleagues ${ }^{16}$ studied the influence of CPB temperature only on markers of neuronal injury in 20 children, and in a recent comparison, Eggum and colleagues ${ }^{18}$ investigated its effects on inflammatory mediators in 30 children. Our study is therefore unique in that we have examined the influence of CPB temperature on markers of inflammation, organ injury, and clinical outcome in a relatively large population of infants and children. Our findings suggest that the temperature has little effect on nonclinical outcomes, as also suggested in these previous studies. This conclusion is further supported by 3 large retrospective studies confirming the feasibility, safety, and potential clinical advantages of warmer $\mathrm{CPB}$ temperature when compared with cooler CPB temperature in pediatric cardiac surgery. $8,9,19$

\section{Study Limitations}

This study does, however, have a number of limitations. First, our advanced CPB strategy, which incorporates antiinflammatory strategies, could theoretically have obviated any detectable difference between our study groups. However, because these strategies are part of routine practice in many centers around the world, we were specifically interested in any additional effects of temperature manipulation. Second, the necessarily longer CPB times in the cooler group may have negated any potential benefit from cooling. However, the association of hypothermia and longer CPB time in our study is consistent with previously published data, and longer CPB time has been shown to be accompanied with enhanced inflammatory response in pediatric cardiac surgery. ${ }^{1,18}$ Further studies determining the appropriate time to begin rewarming to shorten bypass time are therefore warranted with continued use of hypothermic CPB. Third, detailed imaging and later outcome assessments would have provided more conclusive information as to whether brain injury had occurred. This was not practically possible at the time of the study. Fourth, our inability to evaluate the required sample size because of the missing data points reduces the power of the study, increasing the risk of a type II error. We recognize that these are both limitations of the study; however, given that the estimates for all of the outcomes are fairly close to 0 , it is unlikely that a larger sample size and no missing data would lead to a significant result, and in particular one that would be clinically important. Finally, we acknowledge that the use of aprotinin has been abandoned in most pediatric cardiac surgical centers since the termination of our study. Although the use of aprotinin did not differ between study groups, a potential influence on overall end points cannot be excluded. It is important to note that we have not examined "normothermic" CPB and that our findings should not be further extrapolated in support of this approach, with further studies required to compare normothermia with mild hypothermia. 


\section{CONCLUSIONS}

Postoperative SIRS and organ injury remain a problem after pediatric open surgery. This study suggests that moderate hypothermia may not offer any advantage over mild hypothermia during CPB for pediatric cardiac surgery in terms of clinical outcome or effect on the development of acute inflammation or organ injury, questioning whether moderate hypothermia may be routinely applied in this setting.

The authors thank the Anaesthetic Research Group at the Murdoch Children's Research Institute for providing the S100B Protein testing, and especially Andrew Davidson for critical review of the article.

\section{References}

1. Caputo M, Bays S, Rogers CA, et al. Randomized comparison between normothermic and hypothermic cardiopulmonary bypass in pediatric open-heart surgery. Ann Thorac Surg. 2005;80:982-8.

2. de Leval MR. 'Because we can, should we.?' Eur J Cardiothorac Surg. 2006;30: 693-4.

3. Checchia PA, Bronicki RA, Costello JM, Nelson DP. Steroid use before pediatric cardiac operations using cardiopulmonary bypass: an international survey of 36 centers. Pediatr Crit Care Med. 2005;6:441-4.

4. Gaynor JW. Use of modified ultrafiltration after repair of congenital heart defects. Semin Thorac Cardiovasc Surg Pediatr Card Surg Annu. 1998;1:81-90.

5. Jonas RA, Wypij D, Roth SJ, et al. The influence of hemodilution on outcome after hypothermic cardiopulmonary bypass: results of a randomized trial in infants. J Thorac Cardiovasc Surg. 2003;126:1765-74.

6. Wernovsky G, Wypij D, Jonas RA, et al. Postoperative course and hemodynamic profile after the arterial switch operation in neonates and infants. A comparison of low-flow cardiopulmonary bypass and circulatory arrest. Circulation. 1995; 92:2226-35.

7. Corno AF, von Segesser LK. Is hypothermia necessary in pediatric cardiac surgery? Eur J Cardiothorac Surg. 1999;15:110-1.

8. Walther T, Rastan A, Dahnert I, et al. Moderate versus deep hypothermia for arterial switch operation. Thorac Cardiovasc Surg. 2006;54:255-8.

9. Pouard P, Mauriat P, Ek F, et al. Normothermic cardiopulmonary bypass and myocardial cardioplegic protection for neonatal arterial switch operation. Eur J Cardiothorac Surg. 2006;30:695-9.

10. Qing M, Vazquez-Jimenez JF, Klosterhalfen B, et al. Influence of temperature during cardiopulmonary bypass on leukocyte activation, cytokine balance, and post-operative organ damage. Shock. 2001;15:372-7.

11. Qing M, Woltje M, Schumacher K, et al. The use of moderate hypothermia during cardiac surgery is associated with repression of tumour necrosis factor-alpha via inhibition of activating protein-1: an experimental study. Crit Care. 2006;10:R57.

12. Stocker CF, Shekerdemian LS, Visvanathan K, et al. Cardiopulmonary bypass elicits a prominent innate immune response in children with congenital heart disease. J Thorac Cardiovasc Surg. 2004;127:1523-5.

13. Allen ML, Peters MJ, Goldman A, et al. Early postoperative monocyte deactivation predicts systemic inflammation and prolonged stay in pediatric cardiac intensive care [comment]. Crit Care Med. 2002;30:1140-5.

14. Teoh KH, Bradley CA, Gauldie J, Burrows H. Steroid inhibition of cytokinemediated vasodilation after warm heart surgery. Circulation. 1995;92:II347-53.

15. Gazmuri RJ, Gopalakrishnan P. Hypothermia: cooling down inflammation. Crit Care Med. 2003;31:2811-2.

16. Rasmussen LS, Sztuk F, Christiansen M, Elliott MJ. Normothermic versus hypothermic cardiopulmonary bypass during repair of congenital heart disease. J Cardiothorac Vasc Anesth. 2001;15:563-6.

17. Lardner D, Davidson A, McKenzie I, Cochrane A. Delayed rises in serum S100B levels and adverse neurological outcome in infants and children undergoing cardiopulmonary bypass. Paediatr Anaesth. 2004;14:495-500.

18. Eggum R, Ueland T, Mollnes TE, et al. Effect of perfusion temperature on the inflammatory response during pediatric cardiac surgery. Ann Thorac Surg. 2008;85:611-7.

19. Durandy Y, Hulin S, Lecompte Y. Normothermic cardiopulmonary bypass in pediatric surgery. J Thorac Cardiovasc Surg. 2002;123:194. 